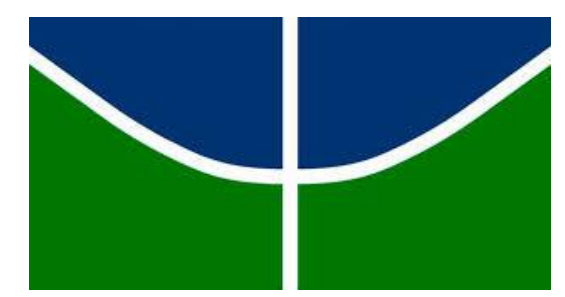

Universidade de Brasília - UnB

Faculdade UnB Planaltina - FUP

Licenciatura em Educação do Campo - LEdoC

CONTRIBUIÇÕES DA FEIRA DE CIÊNCIAS REALIZADA NA ESCOLA MUNICIPAL SANTO ANTÔNIO

Airton Gonsalves da Cunha

Planaltina 


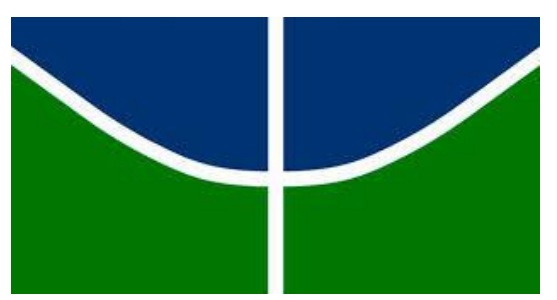

Universidade de Brasília - UnB

Faculdade UnB Planaltina - FUP

Licenciatura em Educação do Campo - LEdoC

\section{CONTRIBUIÇÕES DA FEIRA DE CIÊNCIAS REALIZADA NA ESCOLA MUNICIPAL SANTO ANTÔNIO}

\section{Airton Gonsalves da Cunha}

Monografia apresentada ao Curso de Licenciatura em Educação do Campo, da Universidade de Brasília, como requisito parcial para a obtenção do título de Licenciado em Educação do Campo, com habilitação nas Áreas de Ciências da Natureza e Matemática.

Orientadora: Profa ${ }^{a}$. Dra . Priscilla Coppola de Souza Rodrigues

\section{Planaltina}




\section{AGRADECIMENTO}

Agradeço primeiramente a Deus por ter possibilitado minha existência e consequentemente estar vivo, e a sabedoria e discernimento em fazer o justo, em estar vivendo este momento de transformação intelectual, e superação das dificuldades encontradas nesta caminhada.

Aos meus pais, Leonardo e Denciana pelo apoio incondicional, não medindo esforços para a minha formação acadêmica, desde o início me amparando nos momentos de extrema dificuldade em ficar longe de casa, gostaria que soubessem que tenho um imenso amor por vocês, e que é minha fonte de inspiração para prosseguir sonhando, que a partir dos sonhos que se constroem a realidade.

À minha ilustre orientadora Prof ${ }^{\mathrm{a}}$. Dr ${ }^{\mathrm{a}}$. Priscilla Coppola de Sousa Rodrigues, por ter aceitado contribuir de forma magistral em minha formação acadêmica, e em seu nome agradeço a todos os educadores da LEdoC, que compartilharam práticas e conhecimento no decorrer desses oitos semestres, com um propósito da (re)construção de gente. Nesta luta contra hegemônica, de reconhecimento de pessoas que sempre foram inviabilizada pela sociedade capitalista.

Agradeço também as minhas filhas Eliane de Jesus, Michaelly e Ana Paula pelo amor e compreensão nos momentos de minha ausência, e consequentemente cuidando de nossa chácara para que fosse possível estar estudando fora, elas que são a razão de todo meu empenho e dedicação.

Por fim a secretaria de saúde do Município de Flores de Goiás, na qual estou alocado como motorista, em conceder-me possibilidades de concluir uma graduação em outra unidade da federação. Que durante os oitos semestres foi possível adaptar a escala para atender as minhas necessidades. 


\section{RESUMO}

O presente trabalho apresenta os relatos da Feira de Ciências, realizada com a turma do nono ano da escola Municipal Santo Antônio, situada no Distrito de Goiaminas município de Formoso, Minas Gerais. Sabe-se que uma Feira de Ciências se constitui um espaço democrático para apresentação de trabalhos e ensaios de pesquisas. Dessa forma, o presente trabalho teve como objetivo geral investigar como a água é usada pelos moradores da comunidade Gameleira e realizar uma Feira de Ciências na escola. Os resultados apresentados foram obtidos por meio de apresentação, experimentos, saída de campo e questionários aplicados, antes e após a realização da Feira de Ciências, aos educandos do ensino fundamental II. Sendo que os educandos envolvidos nas atividades foram sujeitos e protagonistas do processo de ensino-aprendizagem, aulas expositivas e práticas com experimentos científicos, saída de campo e foram utilizados elementos e materiais que fazem parte do cotidiano da vida das pessoas que moram no Campo como mina d'agua, falta de água nos períodos de estiagem, natureza e vegetação nativa, utilização de filtro ecológico e identificação do pH de alguns líquidos .

Palavras-chave: Feira de Ciências, ensino de Ciências, educação do campo. 


\begin{abstract}
This paper presents the reports of the Science Fair, held with the ninth year of the Santo Antonio Municipal School, located in the district of Goiaminas, Formoso, Minas Gerais. It is known that a Science Fair is a democratic space for presenting papers and research essays. Thus, the present work had as general objective to investigate how water is used by the residents of the Gameleira community and hold a Science Fair in school. The results presented were obtained through the presentation, experiments, field trips and questionnaires applied before and after the Science Fair, to elementary school students II. Being that the students involved in the activities were subjects and protagonists of the teaching-learning process, expository classes and practices with scientific experiments, exits of the field and were used elements and materials that are part of the daily life of the people who live in the Field as mine water shortage during dry periods, nature and native vegetation, use of ecological filter and identification of $\mathrm{pH}$ of some liquids.
\end{abstract}

Keywords: Science Fair, science education, field education. 


\section{SUMÁRIO}

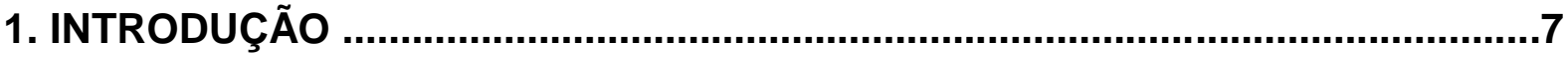

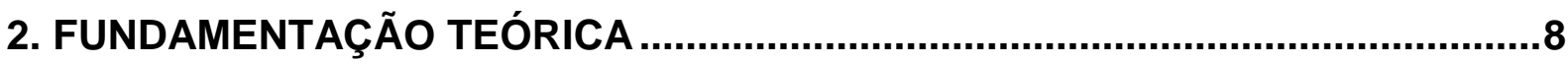

3. METODOLOGIA

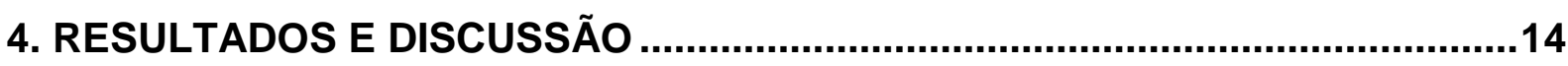

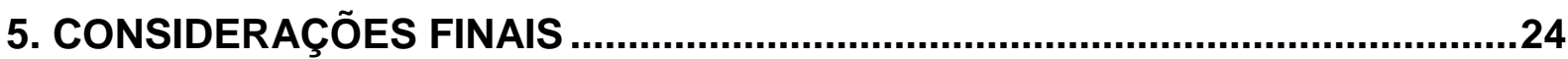

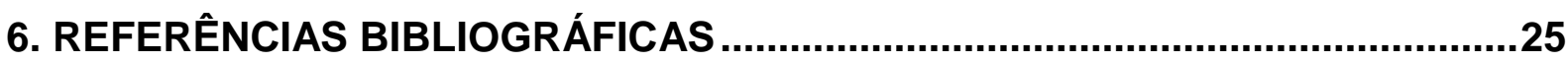

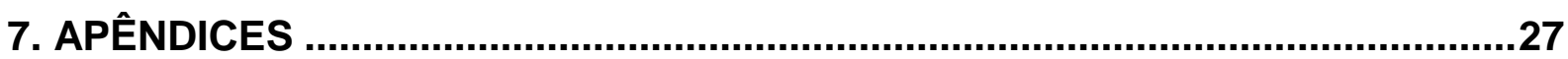




\section{INTRODUÇÃO}

A comunidade Gameleira está a $130 \mathrm{~km}$ de distância da sede do município de Flores de Goiás - GO, sendo que a Escola Municipal Santa Maria possui o ensino fundamental I e II. E a extensão do Colégio Júlio César o ensino médio, estando ela situada no distrito de Santa Maria "Flores de Goiás", distante $40 \mathrm{~km}$ da comunidade Gameleira, sendo a via de acesso quase toda sem pavimentação, fato que aumenta o tempo de deslocamento até as instituições de ensino acima citadas.

$\mathrm{Na}$ comunidade Gameleira funciona a Escola Municipal Sebastião Teodoro Sobrinho, que possui no período matutino o ensino fundamental I, do primeiro ao quinto ano, em sistema multi seriado para as crianças da comunidade.

Porém, os educandos das séries subsequentes precisam se deslocar para outras unidades de ensino. Então, a opção é se deslocar até o distrito de Goiaminas, município de Formoso - MG, situado a $20 \mathrm{~km}$ de distância da comunidade, aonde funciona a Escola Municipal Santo Antônio, que possui o ensino fundamental I e II, e a extensão da Escola Estadual Nossa Senhora da Abadia, que possui o ensino médio.

Os educandos da comunidade, que cursam o ensino fundamental II e o ensino médio, estudam na Escola Municipal Santo Antônio e na Escola Estadual Nossa Senhora da Abadia, devido à proximidade com a comunidade e um melhor acesso, com quatro quilômetros do percurso pavimentado, o que melhora um pouco o deslocamento dos educandos. Atualmente, aproximadamente 40 educandos da comunidade Gameleira estudam em Goiaminas.

Devido a essa proximidade com a comunidade, a Feira de Ciências, que é objeto de estudo do presente trabalho, foi realizada na Escola Municipal Santo Antônio, com os educandos do $9^{\circ}$ ano, e assim foi possível contar com a participação dos educandos da comunidade Gameleira na Feira de Ciências.

Em virtude da troca da coordenadora, por motivo de licença maternidade, e a falta de um substituto, foram necessárias algumas alterações no planejamento inicial do trabalho, de forma que o projeto da Feira de Ciências não foi descartado, mas sim reformulado e adiado para o quarto bimestre, mas a turma do $9^{\circ}$ ano construiu sua apresentação para toda a escola e comunidade na reunião de pais referente ao terceiro bimestre. Com o propósito de aproximação escola e pais, e vice-versa, os 
pais foram convidados a participar, pois a integração escola-comunidade apresenta um ganho significativo para toda a comunidade escolar.

A Feira de Ciências se constitui um espaço para apresentação de trabalhos e ensaios de pesquisa. Portanto, o trabalho teve como objetivo realizar uma Feira de Ciências com os educandos do ensino fundamental II, investigar como a água é usada pelos moradores da comunidade Gameleira, e quais os elementos favoráveis a esta utilização, e assim resgatar a realização das Feiras de Ciências como metodologia no ensino perfeito de Ciências. Sendo que na escola não era realizada uma Feira de Ciências a mais de cinco anos e agora ficou acordado de acontecer anualmente.

\section{FUNDAMENTAÇÃO TEÓRICA}

Barcelos et al. (2010) destacam que as Feiras de Ciências são eventos institucionais, e que com isso, implicam a mobilização de muitas pessoas da comunidade escolar e de outros espaços para sua realização. Como qualquer outra atividade de ensino-aprendizagem que envolva criatividade e investigação na busca de soluções para um problema, há a necessidade da realização de projetos e de interações entre todos os participantes (educandos, educadores, coordenadores e escola), visto que um evento dessa natureza depende de uma série de medidas e providências que devem ser pré-programadas.

Para Farias (2006) as Feiras de Ciências ganharam um impulso mais expressivo após a Segunda Guerra Mundial e, nos anos 50, nos Estados Unidos, ocorreu a primeira Feira de Ciências que incluiu mais de uma dezena de trabalhos de outras feiras do país, com o grande sucesso do evento houve interesse de outras localidades em participar da exposição dos experimentos, assim atraindo mais de 200 expositores de outras feiras estaduais. Esse movimento culminou no desenvolvimento de Feiras de Ciências no âmbito internacional.

No Brasil, as primeiras Feiras de Ciências surgiram em meados da década de 60 , coincidindo com o surgimento dos primeiros centros de Ciências no país (Corsini e Araújo, 2007).

Para Farias (2006) a realização de Feiras de Ciências no Brasil é composta por três fases distintas, as primeiras feiras tinham como objetivo familiarizar os educandos e a comunidade escolar com materiais e laboratórios, o que era bastante 
restrito a população na época, e tinham como finalidade principal avançar no conhecimento cientifico. A segunda fase tinha como fundamento a utilização de aparelhos de laboratório, demonstração de fundamentos e conteúdos encontrados em livros-textos de Ciências. A terceira fase contempla a investigação dos trabalhos, com envolvimento efetivo dos educandos na elaboração de pesquisas.

Assim, as Feiras de Ciências podem ser utilizadas para repetição de experiências realizadas em sala de aula; montagem de exposições com a finalidade de demostrar como o aprofundamento de estudo em busca de novos conhecimentos. Revela a possibilidade de aproximação com a comunidade científica, espaço de iniciação científica, desenvolvimento do espirito criativo, com o propósito de integração escola-sociedade. No entanto, a feira pode fazer parte do currículo, sendo parte integrante do planejamento desde o início do período letivo, para que no momento de apresentação seja o coroamento do trabalho realizado ao longo do período (Farias, 2006).

Entretanto, esse processo pode ser implementado nos currículos escolares, no sentido de possibilitar a interação dos educandos, com novas metodologias onde o conhecimento prevaleça sobre os interesses das pessoas que elaboram os currículos com os modelos tradicionais de educação, nas Feiras de Ciências os educandos são os protagonistas das investigações de questões relevantes e até de novos experimentos.

De acordo com Vasconcelos (2015), para a realização de um projeto de Feira de Ciências, se faz necessário, uma pesquisa bibliográfica sobre o tema a ser abordado, pois é o início de qualquer trabalho. A pesquisa se justifica, em razão de certificar que o conteúdo a ser investigado, submetido à análise é realmente objeto de pesquisa, podendo apresentar resultados diversos, que não seja o esperado nos experimentos.

Para Corsini e Araújo (2007), as Feiras de Ciências vão além das exposições dos resultados, e apresenta ao educandos um envolvimento com o objetivo de produção do conhecimento efetivo.

Segundo Farias (2006), as Feiras de Ciências são capazes de fazer com que o educandos se sintam parte do processo, por meio de trabalhos próprios, com o envolvimento em uma investigação científica, propiciando um conjunto de experiências interdisciplinares, apropriando conhecimento formal. As Feiras de 
Ciências podem proporcionar aos educandos uma exposição de trabalhos realizados por eles na comunidade, possibilitando um intercâmbio de informações.

Para Sousa "s.d." é necessário destacar alguns pontos importantes de uma Feira de Ciências: A troca de ideias, compartilhar reconhecimento do trabalho do outro e de seus próprios limites, realizar experiências científicas com algumas substâncias, interagir com outras pessoas (colegas, educadores, público); aprendizagem na área de comunicação, mudança da visão de educação como mediadora do conhecimento; estímulo à reflexão e à análise crítica produtiva; ampliação dos conhecimentos.

Outro ponto a se destacar que é as Feiras de Ciências podem propor uma iniciativa de aproximação de escola e comunidade, de forma que os pais possam conhecer o processo metodológico desenvolvido na escola, e possam participar da elaboração das propostas a serem implantadas na instituição de ensino, quando há interesse de ambas as partes envolvidas no processo educacional.

A sala de aula deve ser inserida em uma transformação que envolva o trabalho conjunto, construindo uma empreitada desafiadora, porque significa não privilegiar principalmente o educador, mas os educandos. O educandos precisa ser motivado ser investigativo, ter um questionamento crítico e avançar na autonomia da expressão, e tomar a iniciativa de construir seu próprio espaço de sujeito participativo e atuante.

A Feira de Ciências apresenta esse elemento criativo e investigativo das Ciências, metodologia de ensino aprendizagem que poderia ser adotada em todas as escolas. Que possibilite a percorrer novos caminhos do pensar, e do agir e adquirindo conhecimentos em sua jornada do aprendizado, formando uma postura crítica, contestadora e construtivista, em que o educando busque dentro de sua realidade, algo que lhe desperte sua curiosidade e interesse do conhecimento cientifica, segundo Oaigen et al. (2013).

Para Pereira et al. "s.d." o ensino de Ciências no ensino fundamental, por meio da Feira de Ciências é momento em que educandos e educadores irão construir um diálogo cientifico para elaboração de experimentos a serem compartilhados no ensino aprendizagem do coletivo. No processo, o diálogo com os educandos é fundamental tanto para o educador quanto para o educando, pois neste momento o educador deve exercer a sua principal função dentro da sala de 
aula, de orientador no processo de ensino aprendizagem do educando e não de detentor do conhecimento absoluto, assim sendo o objetivo do trabalho é desenvolver a habilidade e a iniciativa criativa e investigativa dos educandos para incentivar as pesquisas na escola, sendo todas as atividades desenvolvidas supervisionadas por educadores.

Em uma aula prática é estimulante inserir no contexto construção de maquetes e modelos de experimentos que auxilia a compreensão do conteúdo trabalhado, onde pode ocorrer erros e acertos, e através dos erros que se estimula a investigação do experimento para tentar descobrir onde ocorreu o erro e por quê houve? Através dos erros estimula a cognição cientifica dos participantes que esperava um resultado e obteve outro. Uma maquete pode ser feita de algo já existente ou de projeto que pretende ser construído, em tamanho adequado para representar algo de fácil compreensão de todos.

\section{METODOLOGIA}

O trabalho foi realizado no $7^{\circ}$ tempo comunidade, da turma Margarida Alves do curso de Licenciatura em Educação do Campo (LEdoC), da Universidade de Brasília (UnB) no ano de 2017, e foi planejado e apresentado à educadora titular da turma. A pesquisa teve como foco a realização da Feira de Ciências com o tema água, sendo que o projeto foi pensado conjuntamente com a direção da escola, e foi realizado no mês de outubro de dois mil e dezessete.

A pesquisa foi realizada no $9^{\circ}$ ano do ensino fundamental, com 17 educandos, da Escola Municipal Santo Antônio, Distrito de Goiaminas, Formoso - MG, sendo que grande parte dos educandos são oriundos de áreas rurais, que compõe a circunvizinhança da escola.

No processo de preparação e realização da Feira de Ciências, foram utilizadas nove aulas de 50 minutos cada, distribuídas da seguinte forma:

$\checkmark$ Duas aulas para apresentação e explicação dos conteúdos que seriam desenvolvidos na Feira;

$\checkmark$ Uma aula para a pesquisa e realização de alguns experimentos;

$\checkmark$ Uma aula para a saída de campo à uma nascente que abastece a comunidade escolar; 
$\checkmark$ Uma outra aula para que os educandos respondessem ao primeiro questionário, apresentado no apêndice;

$\checkmark$ Duas aulas para que eles construíssem as maquetes e

$\checkmark$ As duas aulas finais foram destinadas à apresentação dos experimentos e resultados da pesquisa.

$\checkmark$ E por fim, os educandos responderam ao segundo questionário em um outro momento, devido ao tempo e por não ser necessária uma aula para essa atividade.

Para a realização da Feira de Ciências, foi utilizado um espaço com cobertura, porém aberto, dentro do pátio da escola, de forma que foi possível reunir as turmas do sexto ao nono ano, e seus respectivos educadores para assistirem à apresentação dos trabalhos.

A turma do $9^{\circ}$ ano envolvida na feira foi dividida em quatro grupos, sendo que três deles eram compostos por quatro integrantes e um outro grupo com cinco.

Cada grupo recebeu a incumbência de desenvolver uma atividade sobre a água de forma que todos participou na construção de todos os experimentos e foi pedido que eles escolhessem dentre as seguintes opções a que mais se identificasse: Representar uma nascente desde a superfície até o lençol freático; Construir uma maquete de uma mina de água; Construir um filtro ecológico caseiro ou medir o pH de vários líquidos, utilizados no dia a dia.

$\mathrm{Na}$ construção da maquete da nascente, foram utilizados os seguintes materiais, isopor, tinta guache, lápis preto, palito, linha e pequenos galhos de árvores. Estes materiais empregados de forma a representar uma nascente com os elementos do meio ambiente presente no espaço visitado na saída de campo.

A maquete da mina foi feita com vidro transparente, colado com silicone, espuma para simbolizar o lençol freático, plástico entre a espuma e a terra para melhor visualização do fenômeno de subida da água, um orifício na parte inferior do retângulo com um pedaço de cano, que trespassou o plástico, e alguns brotos de árvores para simbolizar a vegetação e o imprescindível, a água no fundo da maquete, quando soltou o plástico da borda do retângulo o peso da terra fez com que o processo acontecesse.

O filtro ecológico, confeccionado com materiais facilmente encontrados em lojas de matérias de construção e supermercados, garrafa pet transparente cortada 
em maior parte do fundo, algodão, carvão vegetal, areia lavada fina e grossa bem limpa, pedregulho e água suja, sendo a parte cônica da garrafa para fazer o filtro e a outra parte para receber a água filtrada.

A fita de indicador de $\mathrm{pH}$ que pode ser adquirida em loja de caça e pesca, ou de limpeza de piscina. Destaca-se que o custo da fita é bem superior ao do extrato de repolho roxo, mas para certificar que o indicador feito anteriormente estava correto, a fita foi usada.

De posse dessas informações e uma experiência feita em sala com todos os educandos, no dia da feira, foram colocados na bancada doze copos descartáveis e transparentes, com seis líquidos diferentes usados no dia a dia, sendo três incolores e dois de cor alaranjada e uma avermelhada, sem que a plateia soubesse o nome de cada liquido. Então, o grupo explicou o significado de $\mathrm{pH}$, e esclareceu que ele pode ser medido várias formas e que naquele momento ele seria medido utilizandose extrato de repolho roxo e com fita teste $\mathrm{pH}$.

Para obter o extrato do repolho roxo colocou-se em torno de $300 \mathrm{ml}$ de água e duas folhas do repolho roxo no liquidificar e processou, em seguida utilizou-se uma peneira fina e uma colher para separar o líquido do sólido, com a mesma colher adicionou-se uma colher do extrato em cada copo que continha as doze substâncias

Metodologicamente, foi utilizado um formato diferente do corriqueiro da Escola, como saída de campo e aulas práticas em sala, sendo que todas as atividades foram planejadas a partir da realidade dos educandos, propiciando assim que os conteúdos ficassem mais interessantes, segundo relatos dos próprios educandos, pois eles conheceram situações que ficavam só na teoria, da sala de aula, entretanto agora partiu-se para a realidade e pesquisa.

Infelizmente, não foi possível a participação dos pais que seria no dia de entrega de resultados do terceiro bimestre, como inicialmente planejado, mas esse dia foi adiado para a terceira semana de outubro, coincidindo com o período de aulas na faculdade, e devido a mudança de coordenação na escola, também não foi possível realizar a feira no período planejado, que seria no início do ano. No entanto, a feira foi realizada no início do mês de outubro de 2017, sendo que no calendário escolar aconteceram os projetos no início do mês de setembro, exceto Escola Municipal Santo Antônio, devido à essa mudança na programação, a Feira de Ciências ficou restrita às turmas do sexto ao nono ano do ensino fundamental. 
Para a realização de uma Feira de Ciências, se faz necessário, uma boa pesquisa bibliográfica sobre o tema a ser abordado, pois é o início de qualquer trabalho de qualidade, segundo Vasconcelos (2015, p.245). Neste sentido todos os ensaios que antecederam a Feira de Ciências foram minunciosamente pesquisados para ter embasamento na apresentação, processo que foi preparado com antecedência mínima, onde os educandos protagonizaram a pesquisa e a montagem das maquetes, tudo com supervisão dos educadores e coordenadores da Feira de Ciências no ensino fundamental.

\section{RESULTADOS E DISCUSSÃO}

$\mathrm{Na}$ visita à nascente os educandos vivenciaram diversas possibilidades que pode ocorrer, como vereda de vegetação forrageira nativa, brejo com árvores de grande porte e vegetação bem densa e com faixas de transição bem definidas; brejo, vereda e cerrado. A localidade visitada é de propriedade particular, no entanto, protegida com cerca e livre de animais que possam adentrar e pisotear, e consequentemente compactar o solo e impedir o fluxo da água do subsolo para a superfície.

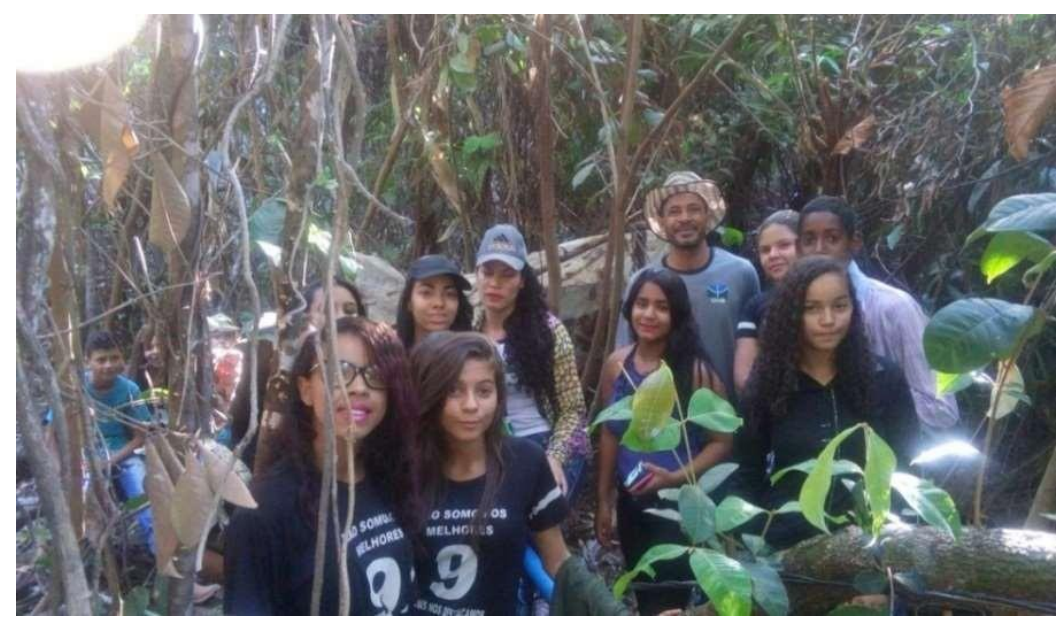

Foto 1 - Saída de campo, visita à nascente do riacho que abastece o Distrito de Goiaminas.

Após a saída a campo, nas aulas seguintes houve uma preparação em sala de outros ensaios de pesquisa com materiais diversos, para compreensão da turma 
em relação ao conteúdo ácido e base, com o propósito de medir o $\mathrm{pH}$ de algumas substâncias de uso diário. Além disso, foi feita a demonstração de como fazer um filtro ecológico, para apresentação na Feira de Ciências, e certificação se os educandos realmente haviam compreendido todo o processo dos experimentos, por que e como acontece, e a utilidade para o seu cotidiano.

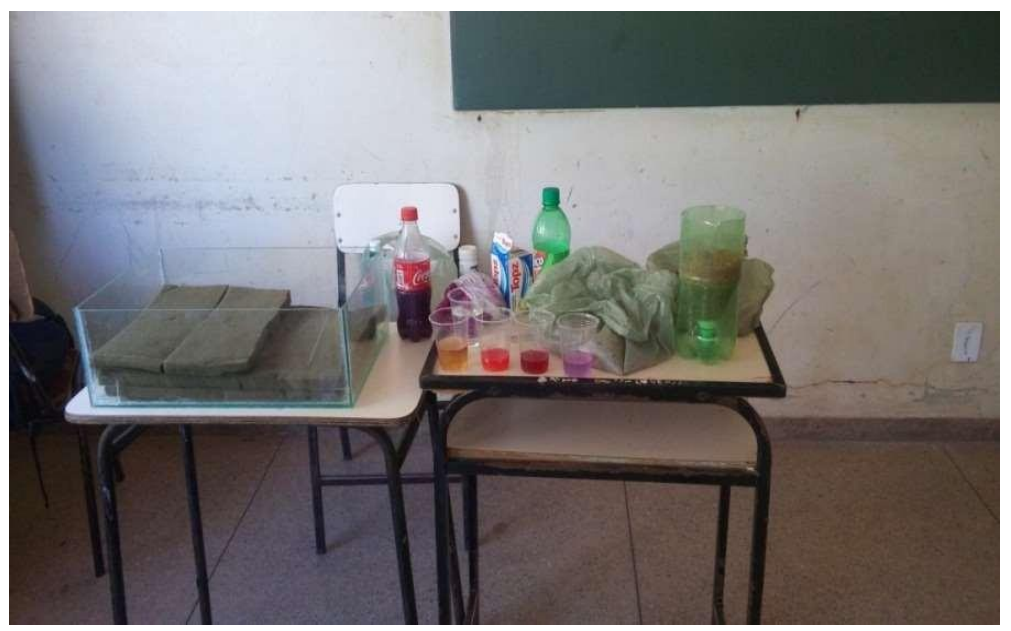

Foto 2 - Materiais utilizados na realização dos experimentos da Feira de Ciências.

Durante a apresentação na Feira de Ciências, após os quatro grupos realizarem os ensaios necessários, eles se organizaram em uma bancada, com os quatro temas e posterior apresentação. A feira teve início com o grupo responsável em demostrar o processo que acontece em uma nascente, desde o lençol freático até a superfície, com uma explicação cientifica dos fatos, como a pressão atmosférica que exerce sobre a terra, possibilitando a vazão da água em locais não compactados por animais.

Para melhor entender o processo foi montada uma maquete de um lençol freático, em um retângulo de vidro transparente, onde foi possível visualizar o lençol freático, o subsolo e a superfície de forma planificada. O material usado foi: espuma, água, plástico com um pequeno orifício de saída, representando assim a mina, e terra na superfície com ilustração de árvores da vegetação das nascentes conforme foto ilustrativa a baixo. 


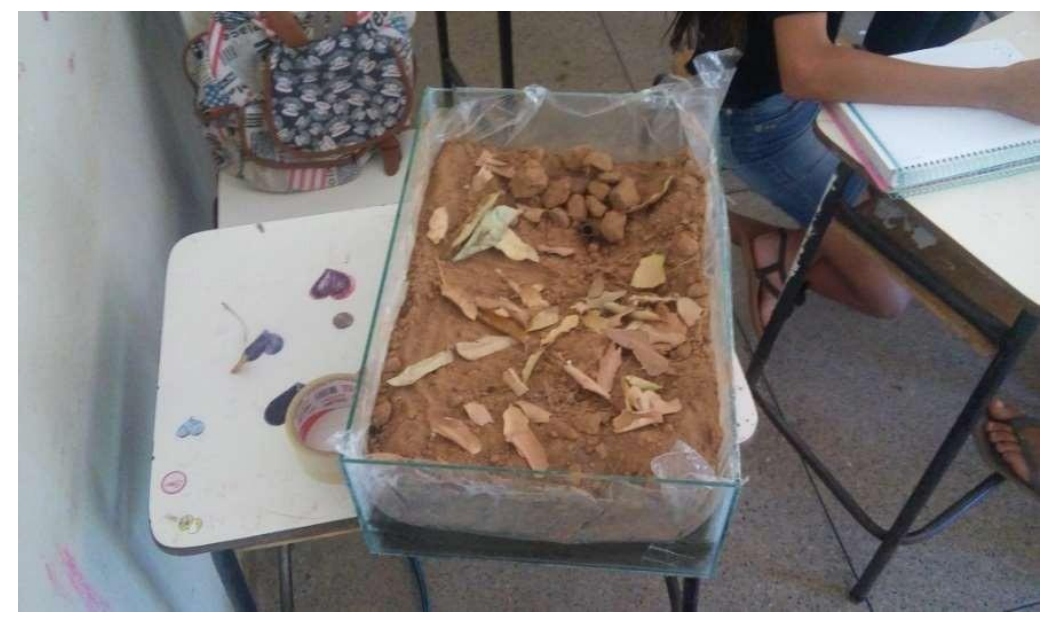

Foto 3 - Maquete da mina.

Na segunda apresentação, o outro grupo construiu uma maquete de uma nascente com todos os elementos visualizados na visita de campo, sendo parte desenhada com tinta, e o restante com materiais como: palitos, linhas, pequenos galhos de árvore e capim; os palitos e linha foram usados para simbolizar as cercas de proteção às nascentes, de forma a impedir a entrada de animais, e com uma distância mínima de 200 metros de acordo com a localidade das nascentes. Dentro da maquete foi construída uma faixa de transição brejo-vereda-cerrado, conforme o ambiente que eles conheceram.

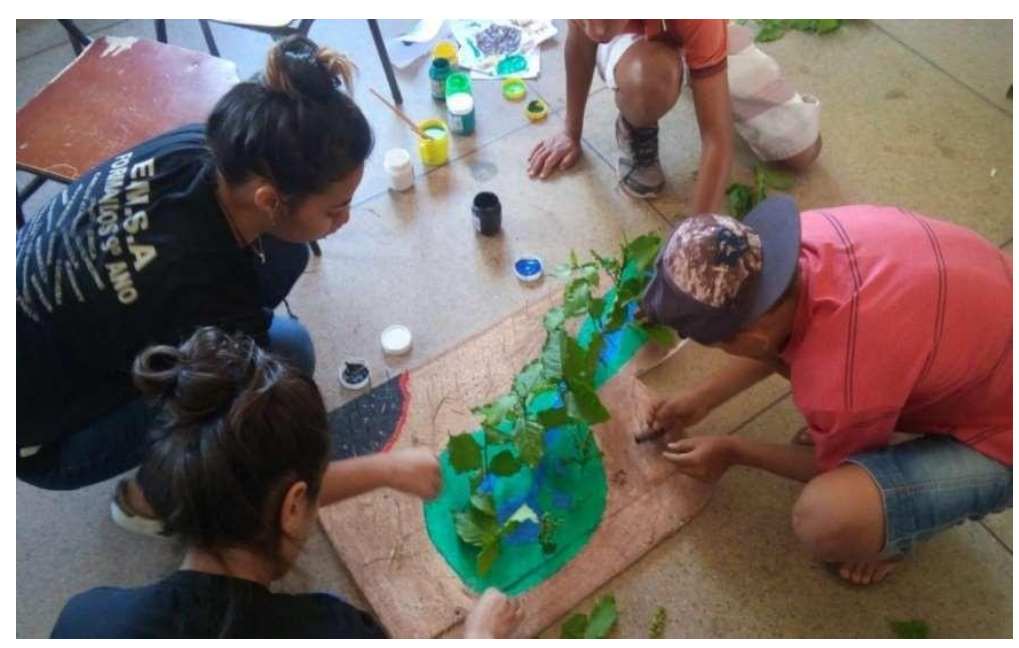

Foto 4 - Construção da maquete de uma nascente.

No Brasil, os recursos hídricos são considerados abundantes, mas porém limitados na maior parte do país, devido ao grande desperdício, sendo que existe 
regulamentação para o uso conforme o código florestal (Lei ํo. 4.771, de 15 de setembro de 1965). Que enquadra as nascentes como área de preservação permanente (APP).

O interesse dos educandos em fazer uma boa demonstração, os estimulou a fazer um desenho de uma nascente, mostrando situações que não devem acontecer, como exemplo, o fogo adentrando a nascente, e fizeram questão de salientar que é um cuidado de todos, no sentido de manter qualquer vestígio de fogo longe dessas vegetações, principalmente no período de estiagem, devido à grande quantidade de matéria orgânica seca, elemento que facilita as queimadas.

Durante a apresentação da maquete da nascente, os educandos responsáveis pela explicação, do processo decorrente dentro da nascente, explicitaram os diversos pontos onde pode ocorrer uma mina de água e sua importância para o curso do rio, que essas minas podem ser em áreas descampadas, ou seja, vereda, ou popularmente brejo com vegetação densa, e solo protegido. No início uma simples mina de água, mas com junção de outras, forma um ribeirão e mais a frente um rio, de grande importância em uma bacia hidrográfica.

O terceiro grupo a se apresentar foi o que confeccionou um filtro ecológico, produzido com materiais de fácil acesso como: garrafa pet de dois litros, algodão, carvão vegetal, areia lavada grossa, areia lavada fina e pedregulho. No processo feito anteriormente à Feira de Ciências, dentro da sala de aula, os educandos aprenderam como utilizar o filtro em suas residências, através de pesquisas realizadas em sites da internet, com várias possibilidades de confecção e usos diversos.

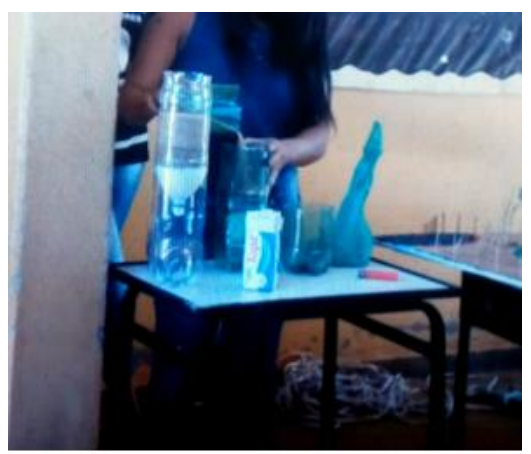

Foto 5 - Construção do filtro ecológico e filtração da água, na apresentação do grupo. 
$\mathrm{Na}$ referida apresentação o grupo utilizou 0 primeiro experimento confeccionado dentro da sala de aula, que foi feito como teste, para demonstrar o caminho que a água fez no processo de filtração. No entanto, enquanto a água ia sendo filtrada, para que a plateia não ficasse dispersa à espera do resultado, eles se dispuseram a fazer um filtro na bancada, onde foi possível acompanhar passo a passo como fazer um filtro ecológico, sendo primeiro utilizada uma garrafa pet de dois litros, cortá-la com a parte do fundo menor, para receber a água filtrada, e a outra parte fazer o filtro, é colocado o algodão em toda parte cônica da garrafa, e logo acima uma fina camada de carvão vegetal, em seguida pedregulho e por último areia lavada grossa e fina.

Feito todos os passos do filtro ocorreu o seguinte, em outro recipiente com água suja de terra, colocou-se a água no filtro, para que pudesse ocorrer a filtração, desde o momento que foi colocada a água para ser filtrada até as primeiras gotas começarem na parte inferior percorreu um espaço de tempo em torno de dois minutos, é importante ressaltar que algumas vezes esta água pode até não sair limpa, caso que ocorreu em nossa experiência na Feira de Ciências, devido a areia utilizada não ter sido previamente lavada e seca, para uma perfeita homogeneização, e consequentemente retenção dos resíduos da água.

Nesse processo de aprendizagem quando a Feira de Ciências estava sendo preparada, em uma aula de demonstração e conceitos sobre os experimentos, a areia utilizada no filtro, havia sido lavada com três dias de antecedência e deixada em local adequado para o secar, com isso a primeira experiência foi um sucesso, no entanto havia sido proposto aos educados que eles mesmos construíssem o filtro com os materiais conseguidos por eles, por isso o experimento feito durante a Feira de Ciências não atingiu o resultado esperado, mas foi explicado que a areia que eles conseguiram era de material de construção e não era limpa o suficiente para que ocorresse a filtração da água. Porém, a segunda filtração que ocorreu foi bem visível. Por fim o processo de filtração da água foi explicado e dito que ele pode ser usado em recipientes maiores, para o consumo doméstico nas residências.

Depois das apresentações houve uma rodada de conversa e perguntas sobre os temas a maquete da nascente e da mina. 
O quarto grupo a se apresentar foi o que fez a medição do pH. Foram usados diversos materiais de pesquisa para entender como fazer esta experiência e conseguir explicar as transformações nos líquidos utilizados. Nas aulas que antecederam à Feira de Ciências, foram apresentados o conteúdo e os materiais, para estudo com explicação ampla, sobre o significado de $\mathrm{pH}$ "potencial Hidrogeniônico", em uma escala numérica que mede o grau de acidez, a neutralidade ou a basicidade de uma determinada solução. Para melhor compreensão da escala foi solicitado que os educandos utilizassem uma tabela colorida, como a da imagem abaixo, com o nome de vários líquidos utilizados no dia a dia, com coloração diferenciada e valor de pH atribuído.

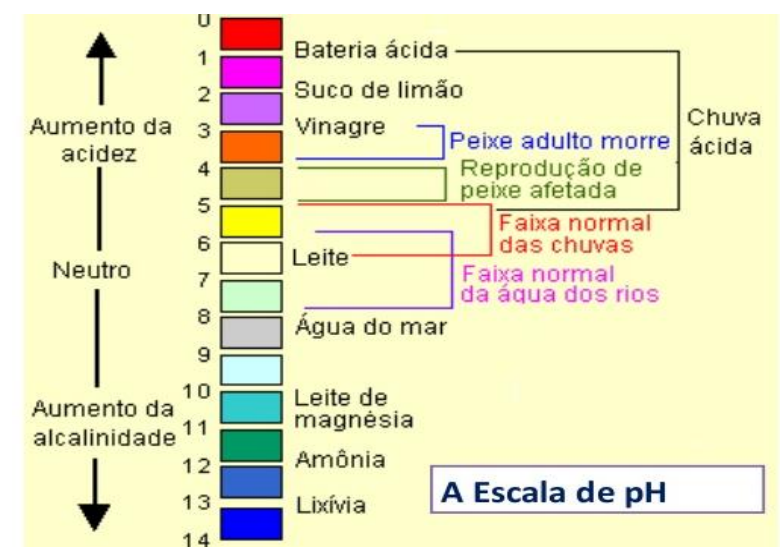

Figura 1 - Escala de $\mathrm{pH}$.

Para obter o extrato do repolho roxo colocou-se em torno de $300 \mathrm{ml}$ de água e duas folhas do repolho roxo no liquidificar e processou, em seguida utilizou-se uma peneira fina e uma colher para separar o líquido do sólido, com a mesma colher adicionou-se uma colher do extrato em cada copo que continha as doze substâncias, e foi verificado que a cor de alguns líquidos mudou em contato com o extrato de repolho roxo. Ao final, a plateia perguntou: Quais eram os líquidos sobre a bancada?

Então um dos membros do grupo disse o nome de cada líquido testado e sua classificação na escala do pH (ver tabela 1).

O grupo mediu o $\mathrm{pH}$ das substâncias usando a fita, que pode ser adquirida em loja de caça e pesca, ou de limpeza de piscina. Destaca-se que o custo da fita é bem superior ao do extrato de repolho roxo, mas para certificar que o indicador feito anteriormente estava correto, a fita foi usada. 


\begin{tabular}{|c|c|c|c|c|}
\hline $\begin{array}{c}\text { Solução } \\
\text { testada }\end{array}$ & $\begin{array}{c}\text { Cor observada } \\
\text { (extrato de } \\
\text { repolho roxo) }\end{array}$ & $\begin{array}{c}\text { Cor observada } \\
\text { (fita de medir } \\
\mathbf{p H})\end{array}$ & $\begin{array}{c}\text { pH medido } \\
\text { com a fita }\end{array}$ & $\begin{array}{c}\text { Tipo de } \\
\text { solução }\end{array}$ \\
\hline Água sanitária & Azul & Azul & 12,5 & Alcalina \\
\hline $\begin{array}{c}\text { Água da } \\
\text { torneira }\end{array}$ & Lilás & $\begin{array}{c}\text { Laranja } \\
\text { avermelhado }\end{array}$ & 7,0 & Neutra \\
\hline Álcool & Amarelo & Amarelo & 5,0 & Ácida \\
\hline Guaraná & Vermelho & Vermelho & 3,0 & Ácida \\
\hline Vinagre & Vermelho & Vermelho & 3,0 & Ácida \\
\hline Limão & Vermelho & Amarelo & 2,0 & Ácida \\
\hline
\end{tabular}

Tabela 1 - Dados coletados durante o experimento realizado durante a Feira de Ciências.

A fita é colocada em contato com as substâncias e ela muda de cor. A cor original é laranja e a variação em sua coloração indica $\circ \mathrm{pH}$ da substância analisada, sendo que laranja escuro tendendo para vermelho, indica $\mathrm{pH}$ neutro ou ideal, se for mais para o amarelo, indica que o pH está baixo e quando for vermelho escuro $\mathrm{pH}$ alto.

Depois de transmitidas todas essas informações ao público, deu-se início as medidas com a fita. $E$ os resultados estão organizados na tabela abaixo: 
Fazendo uma análise dos dois indicadores de $\mathrm{pH}$, apesar das cores não serem todas iguais, os resultados de acidez, neutralidade e alcalinidade/base são iguais e assim verificou-se que o extrato de repolho roxo pode ser usado para medir o pH das substâncias. Além de comparar os resultados obtidos com o extrato de repolho roxo e com a fita de medir $\mathrm{pH}$, comparou-se os resultados experimentais com a literatura (tabela 2), e percebeu-se um bom acordo entre eles.

\begin{tabular}{|c|c|c|c|}
\hline Solução & Cor observada & $\mathbf{p H}$ & Conclusão \\
\hline Água sanitária & Bege & 10,2 & Básico \\
\hline $\begin{array}{c}\text { Água da } \\
\text { torneira }\end{array}$ & $\begin{array}{c}\text { Lilás / Roxo / } \\
\text { Azul }\end{array}$ & 7,5 & Neutro \\
\hline Álcool & Lilás claro & 5,0 & Ácida \\
\hline Refrigerante & $\begin{array}{c}\text { Vermelho / } \\
\text { Rosa claro }\end{array}$ & 2,9 & Ácida \\
\hline Vinagre puro & $\begin{array}{c}\text { Vermelho / } \\
\text { Rosa escuro } \\
\text { Limão puro }\end{array}$ & 2,7 & Ácida \\
\hline
\end{tabular}

Tabela 2 - Prováveis valores a serem encontrados na escala de $\mathrm{pH}$ proposta nesta experiência. Segundo Yoshioka e Lima (p. 11 s.d).

$\mathrm{Na}$ tabela acima, o indicador $\mathrm{pH}$ de repolho roxo forneceu cores mais avermelhadas quando as soluções eram mais ácidas, cores lilás / azuladas para as soluções neutras a ligeiramente básicas, e esverdeadas em pHs mais alcalinos, segundo Yoshioka e Lima (p. 11 s.d). 


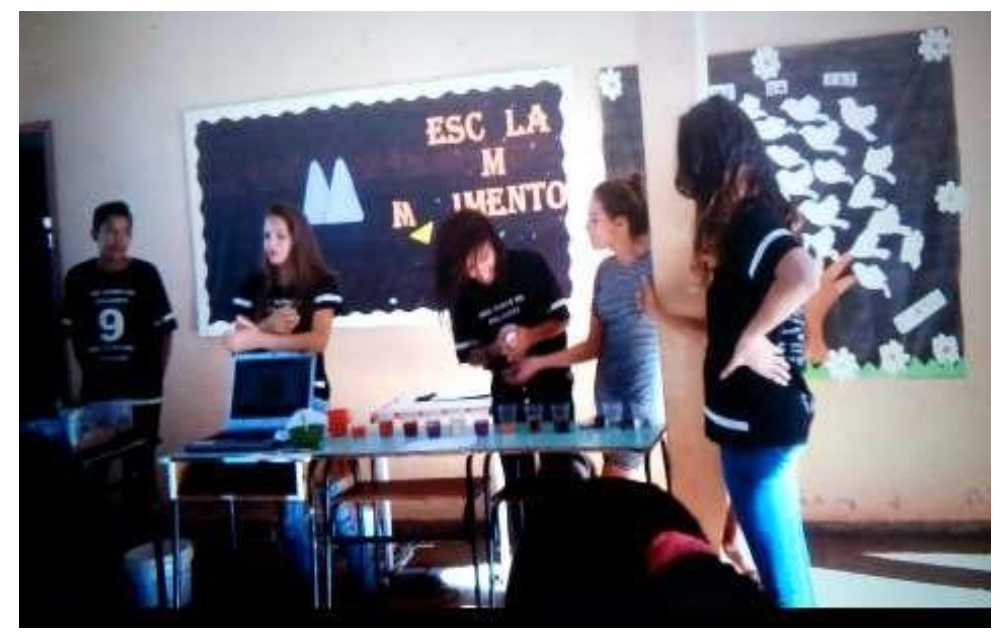

Foto 6 - Segunda medição de indicador de $\mathrm{pH}$, fita.

Durante a Feira de Ciências, os educandos do $9^{\circ}$ ano foram os protagonistas das apresentações e das pesquisas, conseguiram demostrar em pouco tempo o aprendizado que conseguiram absorver nos momentos de preparação da feira, com isso foram estimulados a pesquisar e evidenciaram a partir da liberdade de inovar com relação aos conteúdos propostos, sendo que praticamente toda a turma participou pela primeira vez de uma Feira de Ciências e tiveram uma experiência científica envolvendo os conteúdos do dia a dia dos educandos.

Com relação à análise dos questionários, apresentados no apêndice, que foram respondidos antes da Feira de Ciências, foi possível identificar o quanto foi negligenciado o conhecimento investigativo, pois em um grupo de 17 educandos, apenas três já haviam participado de uma Feira de Ciências, no entanto todos tinham interesse em participar.

Quanto à importância da disciplina de Ciências na vida dos educandos, houve uma discrepância entre a turma, pois dois a consideram de pouca importância e quatro responderam de média importância, e para onze Ciências é muito importante.

No que se refere aos conteúdos relacionados à água, a turma respondeu por unanimidade que gosta de trabalhar com esse tema, pois tem tudo a ver com a existência da vida. Porém, somente três responderam que conseguem relacionar os conteúdos de Ciências com seu cotidiano, sete encontram certo grau de dificuldade e outros sete conseguem relacionar pouco, sendo que a opção de não conseguir ficou em branco. 
Em relação a quem já fez experiência com a água, houveram várias respostas diferentes, sendo que dez responderam que não, enquanto que quatro responderam que já havia feito o filtro ecológico, e três responderam que fizeram outras experiências.

$\mathrm{Na}$ questão que perguntava se os educandos consideram importante usar a água de maneira racional, sem desperdícios, o sim foi unanimidade para turma, onde vários destacaram, que se não houver essa consciência, esse recurso natural essencial para a vida pode não mais existir no futuro.

Partindo do que os educandos trazem de conhecimento sobre os conteúdos trabalhados em ciências e introduzindo a educação do campo com o propósito de reafirmação dos sujeitos do campo no campo, para que eles sejam capazes de transformar as circunstancias sociais desumanizantes, para serem sujeitos capazes de lutar por uma transformação educacional, estimulando o interesse de uma compreensão real dos conteúdos de Ciências no cotidiano, estabelecendo ralação com o meio ambiente e a vida das comunidades dos educandos.

Após a realização da Feira de Ciências os educandos responderam ao segundo questionário, sobre as experiências realizadas por eles, então podemos fazer a relação do antes e depois, o que mudou, houve apropriação do conhecimento cientifico, mudanças sociais e ambientais a partir da apresentação e respostas do questionário. Como estimular cognição cientifica a partir da realidade, e com conteúdo de interesse comum dos educandos na formação. Todas as respostas estão agrupadas nos parágrafos seguintes, conforme analise das respostas deles.

No questionário após a Feira de Ciências, a maioria dos educandos responderam que a realização da feira auxiliou muito no interesse deles aos conteúdos da disciplina de Ciências, é importante registrar que a maioria dos educandos demostraram ter mais interesse em estudar Ciências e gostaram das experiências feitas com água, e sobretudo o conhecimento das nascentes e como acontece para a água fluir, consideraram que após esse aprendizado irão mudar o modo de pensar e proteger a natureza.

Com relação à mudança de percepção da disciplina de Ciências após a Feira, a maioria foi sucinta em dizer que houve mudanças e aflorou o interesse em aprender novas experiências. Com relação ao conhecimento ficaram equilibradas as respostas, entre ótimo e bom, sendo que apenas três consideraram regular, porém 
por unanimidade afirmaram que gostariam de realizar outros experimentos na escola.

A Feira de Ciências instigou a realidade dos educandos com a questão da água, em especial sobre a crise vivenciada nas comunidades, outro ponto em destaque foi o aprendizado sobre indicador de $\mathrm{pH}$, e conhecer o valor do $\mathrm{pH}$ de alguns alimentos do cotidiano de todos; conhecer o passo a passo da construção do filtro ecológico e a conscientização de consumir água filtrada.

Finalizando o questionário, foi solicitado que eles avaliassem a importância de estudar sobre a água, em uma escala de 0 a 5, responderam (5) por unanimidade indicaram o máximo de importância, com algumas reflexões, da água ser um bem natural e essencial para existência de vida, e conscientização para o uso racional da água nas comunidades.

\section{CONSIDERAÇÕES FINAIS}

Este trabalho teve como referência a pesquisa-ação, que desde 0 planejamento da Feira de Ciências na escola, houve um envolvimento do corpo docente, em promover o incentivo investigativo cientifico, no cotidiano escolar dos educandos.

A Feira de Ciências apresentou relevante contribuição no ensino de Ciências para os educandos participantes das experiências.

A pesquisa foi pensada, elaborada e consumada com sujeitos do campo, toda relacionada a seus atos e costumes com o campo, para promover uma ação construtiva nas comunidades camponesas. A partir do pressuposto de entendimento e desempenho nas atividades realizadas e anseio por outros momentos de descobertas e possibilidades de inovar aprender apreendendo na prática, relacionando as teorias adquiridas em sala de aula.

Por fim enfatiza-se que utilizando aulas interdisciplinares, os educandos se apropriam com maior facilidade das Ciências que perpassa o dia a dia, e novas dinâmicas de condução dos educandos em espaços diferentes, que represente a vivência da comunidade, os educandos demonstraram maior interesse na disciplina e gostariam de realizar outros experimentos que facilitem o entendimento dos conteúdos. 


\section{REFERÊNCIAS BIBLIOGRÁFICAS}

BARCELOS, Nora Ney Santos; JACOBUCCI, Giuliano Buzá; JACOBUCCI, Daniela Franco Carvalho; Quando o cotidiano pede espaço na escola, o projeto da Feira de Ciências "vida em sociedade" se concretiza. Ciênc. educ., Bauru, v. 16, n. 1, 2010.

Disponível em:

http://www.scielo.br/scielo.php?script=sci arttext\&pid=S1516-73132010000100013>. Acesso em: 12 de set. 2017.

CORSINI, Aline Mendes do Amaral; ARAÚJJ, Elaine Sandra Nicolini Nabuco de, Feira de Ciências como espaço não formal de ensino: um estudo com educandos e educadores do ensino fundamental, VI Encontro Nacional de Pesquisa em Educação de Ciências, 2007.

FARIAS, Luciana de Nazaré, Feiras de Ciências como uma oportunidade de (re) construção do conhecimento pela pesquisa. 2006, Dissertação (Mestrado em Educação em Ciências e em Matemática) - Universidade Federal do Pará, 2006.

LEI № 4.771, DE 15 de setembro de 1965, com as alterações posteriores (arts. 20 . e 30 .) (Redação dada pela Lei oํ 7.803 de 18.7.1989) do código florestal brasileiro. Disponível em: http://www.incra.gov.br/media/politica_fundiaria/regularizacao_fundiaria/lei_4771_19 65.pdf >. Acesso em: 12 de set. 2017.

OAIGEN, Edson Roberto; BERNARD, Tania; SOUZA, Claudia Alves; Avaliação do evento feiras de ciências: aspectos científicos, educacionais, socioculturais e ambientais. Univates, v. 5, n. 5, 2013. Disponível em: $<$ www.univates.br/revistas/index.php/destaques/article/viewFile/367/361>. Acesso em: 12 jul. 2017.

PEREIRA, Luzilene Cordeiro; BORGES, Viviane Magno; OLIVEIRA JUNIOR, Waldemar Borges de; DIAS, Luan Rodrigo cunha; SOUSA, Jorge Raimundo da Trindade; A importância da feira de ciências para os educandos do $9^{\circ}$ ano do 
ensino fundamental, Universidade Federal do Pará (UFPA), 14ํe encontro de profissionais de química da Amazônia). Disponível em: <http://www.14epqa.com.br/areas-tematicas/ensino-quimica/28-P179-185-aimportancia-da-Feira-de-ciencias-para-os-educandos-do-9-ano-do-ensinofundamental.pdf> . Acesso em 12 jul. 2017.

SOUSA, Alanna Crystine Lima Farias de; MAIA, Glauce Catarine Malheiros; SILVA, Maria Dulcimar de Brito; LEDER, Prisna Jamile Santos; Feira de Ciências como ferramenta para o ensino de química; Universidade do Estado do Pará. Artigo do livro PIBID. "s.d." Disponível em: <http://www.14epqa.com.br/areastematicas/ensino-quimica/50-P337-343-Feira-de-ciencias-como-ferramenta-para-oensino-de-quimica.pdf>. Acesso em 29 mai. 2017.

VASCONCELOS, Marcelo Holanda; FRANCISCO, Welington; Feira de Ciências e ensino por projetos: uma experiência educativa no norte do Brasil. Monografia e Tese de Doutorado, nesta ordem, Universidade Federal do Tocantins - Campus de Gurupi. 2015.

http://www.periodicos.ulbra.br/index.php/acta/article/view/1030/1101. Acesso em 29 de maio de 2017.

YOSHIOKA, Maria Harumi; LIMA, Marcelo Ricardo de; Artigo - Projeto de Extensão Universitária Solo na Escola Universidade Federal do Paraná - Departamento de Solos e Engenharia Agrícola Rua dos Funcionários, 1540 - 80035-050 - Curitiba PR Telefone (41) 3350-5649 - E-mail: solonaescola@ufpr.br http://www.escola.agrarias.ufpr.br/arquivospdf/experimentotecasolos1.pdf . Acesso em 29 de maio 2017 


\section{APÊNDICES}

\subsection{QUESTIONÁRIOS}

\section{QUESTIONÁRIO APLICADO AOS EDUCANDOS ANTES DA REALIZACÃO DA}

\section{FEIRA DE CIÊNCIAS}

NOME:

SÉRIE:

DATA:

1. Você já participou de uma Feira de Ciências? Se não você gostaria?

( ) $\operatorname{sim}$

( ) não

2. Qual a importância da disciplina de Ciências em sua vida?

( ) pouco ( ) médio ( ) muito

3. Você gosta de conteúdos relacionados à água?

( ) $\operatorname{sim}$

( ) não

4. Você consegue relacionar os conteúdos de Ciências com seu cotidiano? ( ) não ( ) pouco ( ) regular ( ) muito

5. Qual experiência você já fez com a água?

6. É importante ter um uso racional da água? Explique sua resposta?

\section{QUESTIONÁRIO APLICADO AOS EDUCANDOS APÓS DA REALIZACÃO DA}

\section{FEIRA DE CIÊNCIAS}

NOME:

SÉRIE:

DATA: 
1. A Feira de Ciências realizada em sua escola auxiliou seu interesse pelos conteúdos e a disciplina de Ciências? Explique?
( ) $\operatorname{sim}$
( ) pouco
( ) não

2. O que mudou para você em relação a disciplina de Ciências depois da Feira de Ciências?

3. Como você avalia a Feira de Ciências para seu conhecimento?
( ) ruim
( ) regular
( ) bom
( ) ótimo

4. Você gostaria de fazer outras experiências cientificas em sua escola?
( ) $\operatorname{sim}$
( ) não

5. Faça uma relação da Feira de Ciências com sua realidade?

6. De 0 a 5 qual a importância de estudar sobre a água? 